\title{
INSURTECH DAN NEW ISLAMIC INSURANCE MODEL: STUDI KASUS SHARING CLAIM DI LAKA BICYCLE INSURANCE, LONDON
}

\author{
Abdul Ghoni \\ Universitas Muhammadiyah Jakarta \\ email: ghoni.brr@gmail.com
}

\begin{abstract}
The growth of Islamic insurance contribution premiums in Indonesia in recent years has begun to decline and the saturation point, this will continue if the insurance industry does not make a new breakthrough. Insurtech and new model schemes are one of the strategies that can be done to re-increase market share in Indonesia. Innovation and new breakthroughs are in the field of insurtech, which is one of the development of technology in insurance with new schemes and models, one of the new models is sharing claims which are now starting to be used as an alternative model of sharia insurance in the future. This claim sharing scheme is a concept of community-based Islamic insurance with technology, so customers can pay premiums less. The purpose of this study was to analyze the strategy of developing a claim sharing model with the Laka Bicycle Insurance case study in London. This research uses descriptive analysis research method with qualitative approaches. The conclusion of this research is that the insurtech development strategy and claim sharing model have the potential to increase the market share of Islamic insurance in Indonesia today, as has been successfully carried out by Laka Bicycle Insurance in London.
\end{abstract}

\begin{abstract}
ABSTRAK
Pertumbuhan kontribusi premi asuransi syariah di Indonesia pada beberapa tahun terakhir sudah mulai mengalami penurunan dan titik jenuh, hal ini akan terus berlanjut sekiranya industri asuransi syariah tidak melakukan terobosan baru, Insurtech dan Skema model baru merupakan salah satu strategi yang dapat dilakukan untuk kembali meningkatkan pangsa pasar di Indonesia. Inovasi dan terobosan baru adalah di bidang insurtech, yaitu salah satu pengembangan teknologi di asuransi dengan skema dan model-model baru, salah satu model baru adalah sharing claim yang saat ini sudah mulai dijadikan salah satu alternatif model asuransi syariah di masa depan. Skema sharing claim ini merupakan konsep asuransi syariah berbasis komunitas dengan teknologi, sehingga nasabah dapat membayar premi dengan lebih murah. Tujuan penelitian ini adalah untuk menganalisis strategi pengembangan model claim sharing dengan studi kasus Laka Bicycle Insurance di London. Penelitian ini menggunakan metode penelitian deskriptif analisis dengan pendekatan kualitatif. Kesimpulan penelitian ini adalah bahwa strategi pengembangan insurtech dan model claim sharing sangat berpotensi meningkatkan pangsa pasar asuransi syariah di Indonesia saat ini, seperti yang telah berhasil dijalankan oleh Laka Bicycle Insurance di London.
\end{abstract}

Keywords: Insurtech, Claim Sharing Model 


\section{A. PENDAHULUAN}

Industri Asuransi Syariah di Indonesia saat ini pertumbuhannya cenderung fluktuatif ${ }^{1}$ dan dalam setahun terakhir mengalami penurunan jika dibandingkan dengan tahun lalu. Untuk meningkatkan share, industri asuransi syariah perlu melakukan banyak terobosan sehingga dapat mereposisi diri di pasar keuangan, salah satunya adalah membuat inovasi baru. $^{2}$ Salah satu inovasi yang dapat dikembangkan saat ini adalah melalui Inovasi keuangan digital, dalam asuransi inovasi berbasis teknologi disebut dengan Insurtech. ${ }^{3}$

\section{Gambar Kontribusi Bruto Asuransi Syariah di Indonesia}

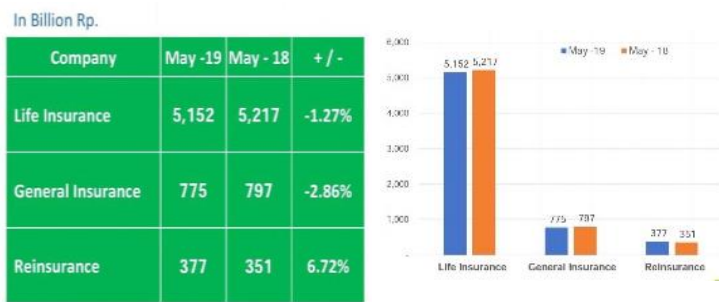

1 Muthmainah. (2016). The Growth of Sharia Insurance in Indonesia 2015 - 2016": An Academic Forecast Analysis. Shirkah, Journal of Economics and Business. ISSN: 2503-4235 (p); 2503-4243 (e).

2 Kamaruddin Sharif. (2004). Takāful Development and Challenges Over 20 Years of Its Existence in Malaysia. Jurnal Pengurusan 23. hlm. 3-13.

${ }^{3}$ Sadaqah-Based Crowdfunding Model for Microfinancing and Health Care, Muhammad Amir Lutfi.

Mohd Adib Ismail, Universiti Kebangsaan Malaysia. JMFIR Vol. 13/No .2 December 2016.
Premi dan Aset Asuransi Syariah di Indonesia

Sumber: Otoritas Jasa Keuangan, data diolah, 2018-2019

Namun, jika kita lihat periode 13 tahun yang lalu, yaitu saat terbitnya Fatwa DSN 52/DSN-MUI/III/ 2006 tentang akad wakalah bil ujrah pada asuransi dan reasuransi syariah, industri asuransi syariah dengan model aqad yang baru, yaitu wakalah bil ujroh mengalami pertumbuhan yang sangat signifikan, baik secara premi maupun aset.

Tabel Perbandingan Pertumbuhan 2

\begin{tabular}{|c|c|c|c|c|c|}
\hline \multirow[b]{2}{*}{ Keterangan } & \multicolumn{3}{|c|}{ periode 5 tahunan } & \multicolumn{2}{|c|}{ dalam Milyar $R p$} \\
\hline & 2007 & 2008 & 2009 & 2010 & 2011 \\
\hline Premi & 805,60 & $1.650,80$ & $2.408,30$ & $2.787,30$ & $5.080,90$ \\
\hline Aset & $1.418,40$ & $1.853,30$ & $3.022,70$ & $3.542,80$ & $9.152,20$ \\
\hline Pertumbuhan premi & & $105 \%$ & $46 \%$ & $16 \%$ & $82 \%$ \\
\hline Pertumbuhan aset & & $31 \%$ & $63 \%$ & $17 \%$ & $158 \%$ \\
\hline \multicolumn{6}{|c|}{ dalam Triliun $R p$} \\
\hline Keteran & 2012 & 2013 & 2014 & 2015 & 2016 \\
\hline Premi & 6,95 & 9,00 & 0,00 & 10,23 & 12,29 \\
\hline Aset & 13,24 & 16,65 & 22,38 & 26,69 & 33,12 \\
\hline Pertumbuhan premi & & $29 \%$ & $11 \%$ & $2 \%$ & $20 \%$ \\
\hline Pertumbuhan aset & & $26 \%$ & $34 \%$ & $19 \%$ & $24 \%$ \\
\hline
\end{tabular}

Sumber: Otoritas Jasa Keuangan, data diolah, 2007-2016

Industri saat itu bergairah dengan skema baru dibandingkan skema lama yaitu mudharabah yang telah digunakan lebih dari 10 tahun oleh Takaful Indonesia. Berdasarkan tabel $1 \mathrm{di}$ atas terlihat bahwa pertumbuhan premi dan aset asuransi syariah dari 2007 s.d 2011 berkisar $16 \%$ s.d $158 \%$ atau rata-rata 
62\%-67\% dan selama 5 tahun tersebut sudah meningkat sebanyak 6 kali. Berbeda hal nya dengan periode tahun 2012 s.d 2016 pertumbuhan premi dan aset asuransi syariah berkisar 2\% s.d 29\% atau rata-rata $16 \%-26 \%$ dan selama 5 tahun tersebut hanya meningkat sebanyak 2 kali. Artinya industri sudah mengalami titik kejenuhan, perlu adanya terobosan dan inovasi baru terkait skema atau model akad baru di industri asuransi syariah Indonesia.

Pengembangan Insurtech Syariah di Indonesia menjadi sebagai kebutuhan dan tuntutan zaman saat ini, bagi semua pemangku kepentingan, seperti OJK, DSN-MUI, dan Industri asuransi syariah sendiri. Hal inilah yang melatarbelakangi penulis melakukan penelitian mengenai claim sharing yang merupakan salah satu bentuk Insurtech syariah, dengan studi kasus Laka Bicycle Insurance di London untuk dapat menjadi benchmark bagi industri asuransi syariah di tanah air kita, sekaligus sebagai langkah inovasi keuangan Syariah digital Indonesia.

\section{B. LANDASAN TEORI}

Penulis mengambil beberapa penelitian terdahulu yang relevan dengan topik penelitian ini. Penelitian yang dilakukan Emanuel Stoeckli \& Christian Dremel \& Falk Uebernickel yang berjudul exploring characteristics and transformational capabilities of InsurTech innovations to understand insurance value creation in a digital world ${ }^{4}$, dalam penelitian ini dijelaskan bagaimana karakteristik dan kapabilitas inovasi dari insurtech dalam memberikan value kepada nasabah dalam dunia digital, khususnya melalui sosial media. Penelitian ini dapat menjadi rujukan bagi penulis terkait dengan objek penelitian yang juga menggunakan social media sebagai saran channel distribution, penelitian yang dilakukan oleh Tan Choon Yan, Paul Schulte, David LEE Kuo Chuen yang berjudul InsurTech and FinTech: Banking and Insurance Enablement. Handbook of Blockchain, Digital Finance, and Inclusion ${ }^{5}$, di dalam penelitian ini dijelaskan dengan sangat

${ }^{4}$ Emanuel Stoeckli \& Christian Dremel \& Falk Uebernickel. (2018). Exploring characteristics and transformational capabilities of InsurTech innovations to understand insurance value creation in a digital world". Institute of Information Management, University of St. Gallen, Müller-Friedberg-Strasse 8, 9000 St Gallen, Switzerland, Published June 2018. https://doi.org/10.1007/s12525-018-0304-7.

5 Tan Choon Yan, Paul Schulte, David LEE Kuo Chuen. (2018). InsurTech and FinTech: Banking and Insurance Enablement". Handbook of Blockchain, Digital Finance, and Inclusion, Volume 1. Copyright (C) 2018 Elsevier Inc. DOI: 10.1016/B978-0-12-810441-5.00011-7. 
lengkap dan rinci terkait insurtech, baik dari sisi aktivitasnya, trend ke depan, benefit dan model-model insurtech. Penelitian ini menjadi acuan secara teoritis terkait insurtech dalam penelitian penulis.

Selain itu, penelitian yang dilakukan oleh B. Nicoletti yang berjudul The Future of FinTech: A Business Model for Insurtech Initiatives $^{6}$, di dalam penelitian ini dijelaskan mengenai beberapa bisnis model Insurtech, yaitu Mobility, Big Data Analytics, IoT (Internet of Thing), Social media, Robots dan AI, Blockchain, Cloud computing. Dari penelitian ini, penulis mendapatkan acuan terkait bisnis model apa saja yang digunakan oleh friendsurance di Germany yang merupakan objek penelitian penulis. Kemudian penelitian yang dilakukan oleh Muthmainah yang berjudul "The Growth of Sharia Insurance in Indonesia"7. Di dalam penelitian ini dijelaskan dengan menggunakan metode analisis Arima

6 B. Nicoletti. (2017). The Future of FinTech: A Business Model for Insurtech Initiatives. DOI 10.1007/978-3-319-51415-4_8

7 Muthmainah. (2016). The Growth of Sharia Insurance in Indonesia 2015 - 2016": An Academic Forecast Analysis. Shirkah, Journal of Economics and Business. ISSN: 2503-4235 (p); 2503-4243 (e) mengenai pertumbuhan industri asuransi syariah di Indonesia yang fluktuatif. Penulis menjadikan penelitian ini sebagai rujukan terkait pertumbuhan industri asuransi syariah di Indonesia juga penggunaan metode penelitian yang sama.

Penelitian yang dilakukan oleh Futoshi Okada yang berjudul "Collaborative Dynamic Capabilities for Service Innovation: Business Model Changes Through Collaborative Dynamic Capabilities Through Insurance Company Use of IT (InsurTech) in the Medical and Health Sectors". Dalam penelitian ini dijelaskan bagaimana insurtech dapat memberikan banyak kelebihan kepada perusahaan asuransi dalam menyediakan produk dan layanan baru bagi nasabah termasuk untuk melakukan efisiensi bisnis yang signifikan. Penelitian ini mengkhususkan dalam kajian insurtech terhadap industri asuransi kesehatan di Jepang, dimana semakin hari biaya kesehatan semakin meningkat, sehingga penggunaan

8 Futoshi Okada. (2018). Collaborative Dynamic Capabilities for Service Innovation": Business Model Changes Through Collaborative Dynamic Capabilities Through Insurance Company Use of IT (InsurTech) in the Medical and Health Sectors. Nihon University, College of Commerce, Tokyo, Japan, 2018. https://doi.org/10.1007/978-3-319-77240-0_6. 
teknologi dapat membantu meningkat pelayanan dan efisiensi biaya di sektor asuransi kesehatan di Jepang. Penulis melalui penelitian ini dapat memperoleh gambaran bahwa insurtech dalam produk asuransi kesehatan yang merupakan produk kumpulan (group) sangat memiliki dampak yang kuat, objek penelitian penulis terkait peer to peer insurance (crowdtakaful) merupakan konsep yang diterapkan di produk kumpulan (group) sehingga penelitian ini dapat dijadikan acuan bagi penulis.

Penelitian-penelitian lain yang juga mendukung penelitian penulis mengenai pengembangan insurtech yaitu yang dilakukan oleh A. Cappiello yang berjudul Technology and the Insurance Industry: Digital Disruption and InsurTech Start-ups: Risks and Challenges $^{9}$, dalam penelitian ini dijelaskan bahwa insurtech tidak merupakan ancaman bagi perusahaan asuransi yang menjalankan bisnis secara traditional, sekiranya pihak asuransi dapat bersinergi dan beradaptasi dengan perusahaan insurtech tersebut. Masa transisi menjadi penting bagi perusahaan

\footnotetext{
${ }^{9}$ A. Cappiello. (2018). Technology and the Insurance Industry: Digital Disruption and InsurTech Start-ups: Risks and Challenges, 2018. https://doi.org/10.1007/978-3-319-74712-5_3.
}

asuransi yang secara traditional memiliki gap teknologi yang tertinggal jauh, akan dihadapi dengan penurunan pendapatan yang signifikan, namun dengan membangun jalur distribusi digital sekaligus tetap mengelola jalur distribusi traditional dapat menjadi sebuah jalan terbaik bagi perusahaan asuransi. Penelitian ini menjadi rujukan bagi penulis untuk menetapkan strategi yang tepat dalam implementasi crowdtakaful di Indonesia dimana sebagian besar perusahaan asuransi syariah di Indonesia masih memiliki gap teknologi yang jauh tertinggal.

Penelitian ini dibandingkan dengan berbagai penelitian terdahulu, khususnya penelitian-penelitian yang diuraikan di atas, maka dapat disimpulkan bahwa penelitian ini dapat dikategorikan sebagai penelitian yang memiliki originalitas yang tinggi, dikarenakan belum ada satupun penelitian baik itu di jurnal nasional dan juga Internasional yang meneliti secara khusus mengenai claim sharing pada asuransi syariah. Penelitian ini menjadi penelitian pertama yang berpotensi akan dapat dikembangkan lebih mendalam dengan penelitian-penelitian selanjutnya, seiring dengan meningkat kebutuhan 
oleh industri asuransi syariah, baik itu di Indonesia maupun di tingkat global.

\section{METODOLOGI PENELITIAN}

\section{Jenis dan Tempat Penelitian}

Jenis penelitian ini menggunakan metode penelitian deskriptif analisis dengan pendekatan kuantitatif, yaitu dengan menggunakan pendekatan phenomenologi ${ }^{10}$. Edmund Husserl dalam Muhadjir menyatakan bahwa Ilmu tidak terbatas pada yang empirik (sensual), melainkan mencakup phenomena yang tidak lain daripada persepsi, pemikiran, kemauan, dan keyakinan subyek tentang sesuatu di luar subyek, ada sesuatu yang transenden disamping yang aposteriorik. $^{11}$

\section{Objek Penelitian}

Penulis mengambil penelitian yaitu perusahaan start-up di London, Laka Bicycle Insurance, merupakan Insurtech pertama di dunia dengan skema sharing

10 Untuk mengkaji praktek-praktek terbaik (the best practices) dalam inovasi keuangan digital melalui konsep P2P asuransi digunakan pendekatan phenomologik melalui penelusuran pustaka dan studi lapangan akan diperoleh data tentang berbagai fenomena empiris dimana fiturfitur P2P asuransi berhasil mencapai tujuan dan sasarannya sehingga teruji (proven) baik konsep maupun modelnya.

11 Noeng Muhadjir. (1996). Metodologi Penelitian Kualitatif, edisi III (Yogyakarta: Rake Sarasin, 1996), claim yang dapat menjadi rujukan bagi pengembangan skema sharing claim di Indonesia.

\section{Metode Pengumpulan Data}

Dalam penelitian ini, penulis melakukan pengumpulan data dengan cara beriikut:

a. Indepth interview, yaitu metode pengumpulan data dengan cara mengadakan wawancara secara mendalam dengan berbagai pihak yang terlibat dalam pengembangan skema sharing claim, yaitu Laka Biycle Insurance, OJK, dan DSN. Dalam wawancara mendalam ini penulis akan menggali strategi yang tepat dalam pengembangan sharing claim pada asurasi syariah di Indonesia.

b. Observasi (observation), untuk mengetahui secara detail langsung aktivitas subjek penelitian, maka penulis telah melakukan observasi mendalam pada subjek-subjek pada objek penelitian, dalam hal ini, Laka Bicycle Insurance di London, penulis telah melakukan wawancara dengan country director perusahaan di Kualalumpur, Malaysia. 
c. Studi dokumentasi, metode ini digunakan untuk memperoleh data sekunder, yaitu data asuransi syariah dan insurtech serta skema sharing claim, meliputi gambaran umum perusahaan, kinerja, kebijakan manajemen dan lainnya.

\section{Sumber Data}

Penelitian ini menggunakan sumber data sebagai berikut:

a. Data Primer, merupakan data yang diperoleh langsung dari sumbernya, diamati dan dicatat untuk pertama kalinya. Dalam hal ini data primer adalah hasil kuesioner dan wawancara serta dokumentasi dari obeservasi dengan obyek penelitian.

b. Data Sekunder, merupakan data yang diusahakan sendiri oleh penulis dengan memanfaatkan data-data yang telah disediakan pihak lain, yaitu melalui buku, jurnal, literatur dan arsip yang ada yang berhubungan dengan obyek penelitian.

\section{Teknik Pengolahan Data}

Dalam penulisan ini semua data yang diperoleh akan diolah dengan menggunakan metode kualitatif dengan menggunakan phenomenologi untuk memberikan jawaban atas rumusan masalah dalam penelitian ini.

\section{PEMBAHASAN}

Claim sharing merupakan termasuk dalam satu bentuk peer to peer ( $\mathrm{P} 2 \mathrm{P})$ model yang digunakan dalam jenis-jenis insurtech. $^{12}$ Insurtech sendiri terbagi dalam 3 kategori besar, yaitu customer experience, business process, dan new products.

\section{Gambar Kategori dan Klasifikasi Insurtech}

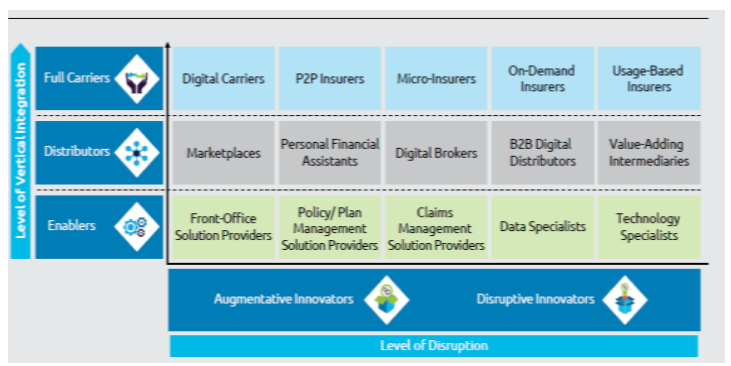

Sumber: Capgemini Financial Services Analysis, 2018.

Selain konsep yang berbeda Insurtech juga diperkuat melalui berbagi teknologi terkini sebagai tools, sehingga menjadikan pelayanan terhadap nasabah semakin kuat, seperti blockchain,

12 Martin Eling and Martin Lehmann. (2018). The Impact of Digitalization on the Insurance, The Geneva Papers, 2018, 43, (359396). The International Association for the Study of Insurance Economics 1018-5895/18. 
artificial intelligence, robotic dan data analytic.

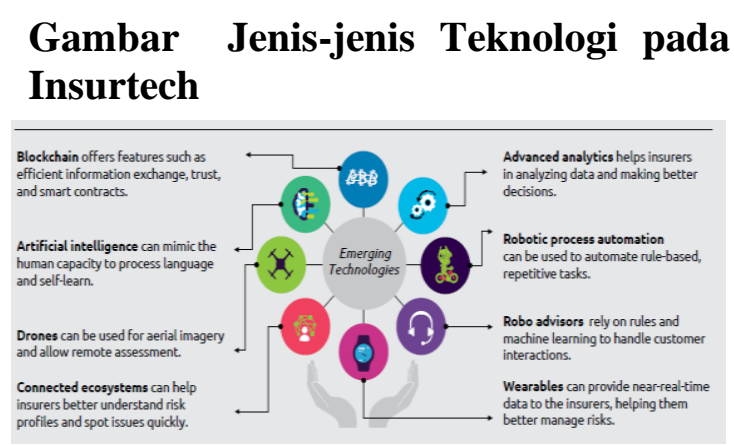

Sumber: Capgemini Financial Services Analysis, 2018

Salah satu yang sukses menerapkan model claim sharing adalah Laka Bicycle Insurance di London, yang diprakarsai oleh Tobias Taupitz, Jens Hartwig dan Ben Allen, melalui basis komunitas sepeda mereka menjual produk asuransi sepeda, sejak 8 Januari 2018 berdasarkan regulasi MGA melalui FCA Sandbox. Mereka melihat saat ini asuransi di mata nasabah saat membayar klaim menghadapi kesulitan dan terkesan memohon dengan posisi di bawah, berbeda dengan konsep claim sharing yang mereka tawarkan, perusahaan asuransi baru mendapatkan pendapatan, saat nasabah menerima klaim. Saat nasabah komunitas bergabung dan diterbitkan polis, mereka tidak perlu membayar premi di awal, namun saat terjadi klaim, perusahaan akan membayarkan terlebih dahulu melalui modal kerja mereka, setelah akhir bulan total klaim yang dibayarkan akan di bagi secara proporsional ke semua peserta, nilai yang dibayarkan termasuk fee perusahaan sebesar $25 \%$ dari jumlah klaim. Maksimum sharing claim plus fee tersebut tidak boleh melebihi nilai premi bulanan dari rate standar industri asuransi, karena perusahaan telah bekerjasama dengan perusahaan reasuransi melalui skema stop loss. Mereka mengklaim melalui skema ini nasabah telah menghemat $60 \%$ dibandingkan dengan premi yang sama pada produk asuransi sejenis.

\section{Gambar Skema Claim Sharing Model Laka Bicycle Insurance}

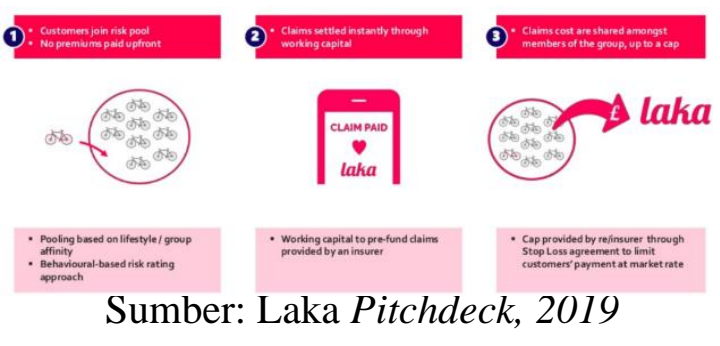

Skema diatas lebih menarik dibandingkan dengan skema di asuransi yang sudah berjalan saat ini, bahkan mereka membuat perbandingan model antara model lama asuransi saat ini (old world) dengan model mereka yang di anggap model baru (new world), seperti yang tergambar di bawah ini: 


\section{Gambar Perbandingan antara Model \\ Asuransi saat ini (old world) dengan Model Claim Sharing (new world)}

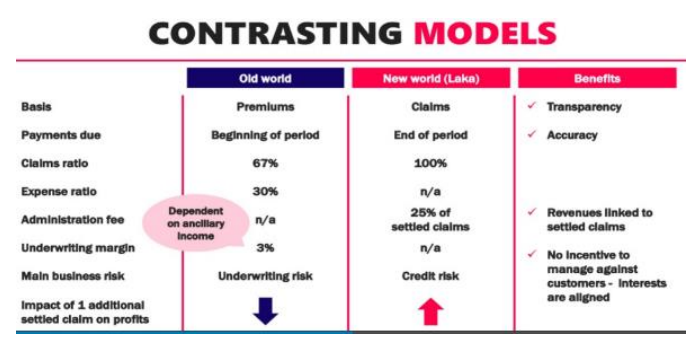

Sumber: Laka Pitchdeck, 2019

Perbandingan diatas menjelaskan bahwa dengan model claim sharing, pihak nasabah akan mendapatkan benefit terlebih dahulu dan semua transaksi lebih transparan dan akurat, sehingga di mata nasabah model ini lebih fair play. Mereka mengklaim bahwa model ini sangat sesuai dengan prinsip-prinsip syariah dan telah di review oleh ahli dibidang figh (scholars). Dikarenakan model ini sangat bagus dan sukses serta sesuai dengan prinsip-prinsip syariah, menjadi hal yang penting untuk diteliti lebih lanjut untuk dapat dikembangkan skema diatas dengan konsep Syariah dan regulasi yang sesuai di Indonesia.

Di London juga berjalan konsep peer to peer insurance (P2PI), yaitu Bought by Many yang menawarkan produk asuransi mikro kepada komunitas yang tertarik dengan spesifik dan kebutuhan khusus terkait asuransi dengan back-up reasuransi dari MunichRe. ${ }^{13}$ Selain itu di Germany ada juga konsep peer to peer berbasis cash back dari premi, yaitu Friendsurance.

Selain konsep insurtech diatas, pengembangan ecosystem merupakan hal yang penting khususnya dibidang fintech syariah. Secara global sudah ada 93 fintech syariah dan 65 diantaranya menggunakan konsep peer to peer, baik secara financing maupun insurance, yang cukup menggembirakan adalah ekosistem inovasi keuangan digital syariah ini paling banyak ada di Indonesia, yaitu sebesar 31, tertinggi di dunia diikuti oleh Amerika, UEA, London dan Malaysia. Untuk insurtech syariah sendiri ada 3 entitas, yaitu yang pertama di London, InsureHalal, di India Uplift Mutuals dan terakhir di Amerika, Lemonade, belum ada satupun insurtech syariah yang resmi terdaftar di Indonesia. Hal ini menjadi tantangan bagi kita dimana secara ekosistem sudah cukup banyak di bidang

${ }^{13}$ IBM Institut_Friend or foe Insurtechs and the global insurance industry. Emanuel Stoeckli \& Christian Dremel \& Falk Uebernickel. Exploring characteristics and transformational capabilities of InsurTech innovations to understand insurance value creation in a digital world. Electronic Markets (2018) 28:287-305. https://doi.org/10.1007/s12525-018-0304-7. 
fintech syariah, namun di Insurtech syariah Indonesia masih tertinggal.

\section{Gambar Ekosistem Fintech Syariah}

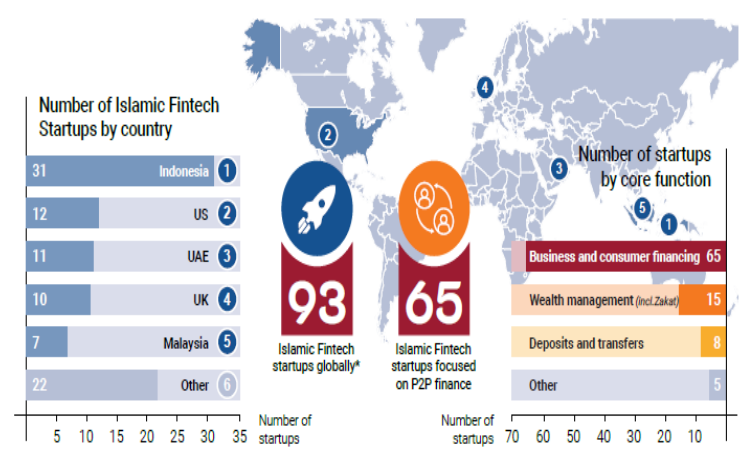

Gambar 3. Ekosistem Fintech Syariah

Sumber: DinarStandar, Islamic

Fintech Report, 2018

\section{E. KESIMPULAN}

Dari uraian diatas dapat disimpukan bahwa strategi dalam pengembangan model inovasi keuangan Syariah digital yang tepat bagi perusahaan asuransi syariah di Indonesia, yaitu sebagai berikut:

1. Inovasi dibidang model bisnis baru di asuransi syariah menjadi faktor utama, sebagai strategi differensiasi model bisnis dan harus dilandasi oleh manfaat yang optimal bagi nasabah.

2. Inovasi dengan mengunakan teknologi baru sebagai basis peningkatan layanan menjadi faktor penting, sehingga pengembangan industri asuransi syariah menjadi lebih efektif dan efisien.

3. Pengembangan inovasi asuransi syariah masih banyak mengalami kendala dan permasalahan, khususnya dalam hal pengembangan dan inovasi di bidang teknologi, dikarenakan faktor sumber daya manusia yang sebagian besar belum memahami perkembangan teknologi terkini dibidang asuransi.

Strategi pengembangan insurtech dan model claim sharing sangat berpotensi meningkatkan pangsa pasar asuransi syariah di Indonesia saat ini, seperti yang telah berhasil dijalankan oleh Laka Bicycle Insurance di London.

\section{DAFTAR PUSTAKA}

A. Cappiello. (2018). Technology and the Insurance Industry: Digital Disruption and InsurTech Start-ups: Risks and Challenges, 2018. https://doi.org/10.1007/978-3-31974712-5_3

B. Nicoletti. (2017). The Future of FinTech: A Business Model for Insurtech Initiatives, 2017. DOI 10.1007/978-3-319-51415-4_8

Emanuel Stoeckli \& Christian Dremel \& Falk Uebernickel. (2018). Exploring characteristics and transformational capabilities of InsurTech innovations to understand insurance value creation in a digital world. Institute of Information Management, 
University of St. Gallen, MüllerFriedberg-Strasse 8, 9000 St Gallen, Switzerland, Published June 2018. https://doi.org/10.1007/s12525-0180304-7

Futoshi Okada. (2018). Collaborative Dynamic Capabilities for Service Innovation: Business Model Changes Through Collaborative Dynamic Capabilities Through Insurance Company Use of IT (InsurTech) in the Medical and Health Sectors. Nihon University, College of Commerce, Tokyo, Japan, 2018. https://doi.org/10.1007/978-3-31977240-0_6

IBM Institut_Friend or foe Insurtechs and the global insurance industry. Emanuel Stoeckli \& Christian Dremel \& Falk Uebernickel. Exploring characteristics and transformational capabilities of InsurTech innovations to understand insurance value creation in a digital world. Electronic Markets (2018) 28:287-305.

https://doi.org/10.1007/s12525-0180304-7

Kamaruddin Sharif. (2004). Takāful Development and Challenges Over 20 Years of Its Existence in Malaysia. Jurnal Pengurusan, 23.

Muthmainah. (2016). The Growth of Sharia Insurance in Indonesia 20152016: An Academic Forecast Analysis. Shirkah, Journal of Economics and Business. ISSN: 2503-4235 (p); 2503-4243 (e)

Mohd Adib Ismail. (2016). Universiti Kebangsaan Malaysia. JMFIR, 13/ 2.

Martin Eling and Martin Lehmann. (2018). The Impact of Digitalization on the Insurance, The Geneva Papers, 2018, 43, (359-396). The
International Association for the Study of Insurance Economics 10185895/18.

Noeng Muhadjir. (1996). Metodologi Penelitian Kualitatif, edisi III (Yogyakarta: Rake Sarasin, 1996),

Sadaqah-Based Crowdfunding Model for Microfinancing and Health Care, Muhammad Amir Lutfi

Tan Choon Yan, Paul Schulte, David LEE Kuo Chuen. (2018). InsurTech and FinTech: Banking and Insurance Enablement. Handbook of Blockchain, Digital Finance, and Inclusion, Volume 1. Copyright (C) 2018 Elsevier Inc. DOI: 10.1016/B978-0-12-8104415.00011-7 